\title{
Evaluation of Some Rice (Oryza sativa L.) Genotypes for Drought Tolerance
}

\author{
Kalpana Maurya $^{1 *}$, Hem C. Joshi ${ }^{1}$, S.C. Shankhdhar ${ }^{1}$, S. K. Guru ${ }^{1}$, \\ A.K. Guar ${ }^{2}$, M.K.Nautiyal ${ }^{3}$ and Atul Kumar ${ }^{1}$ \\ ${ }^{1}$ Department of Plant Physiology, ${ }^{2}$ Department of Molecular Biology \& Genetic Engineering, \\ ${ }^{3}$ Department of Genetics \& Plant Breeding, College of Agriculture, G.B. Pant University of \\ Agriculture and Technology, Pantnagar, Uttarakhand (U.K.), India-263145, India \\ *Corresponding author
}

\begin{tabular}{l}
\hline Key w or d s \\
$\begin{array}{l}\text { Rice, Drought, } \\
\text { Grain yield, Leaf } \\
\text { rolling, Dry matter }\end{array}$ \\
\hline Article Info \\
\hline $\begin{array}{l}\text { Accepted: } \\
\text { 26 January } 2021 \\
\text { Available Online: } \\
\text { 10 February } 2021\end{array}$ \\
\hline
\end{tabular}

A B S T R A C T

Rice is one of the most widely consumed cereal crops providing a staple diet for half of the world's population. Rice is highly susceptible to drought stress during reproductive/flowering stage, leading to significant reduction in plant height and grain yield. Leaf rolling is one of the acclimation responses and is used as a criterion for scoring drought tolerance. An osmoprotecant proline helps to cope with stress condition when plants are exposed to drought. A pot experiment was conducted to study the effect of drought stress on growth, yield and proline accumulation at flowering stage in eight rice genotypes viz. IET 24098, IET 24100, PHY 5, PHY 6, PHY 7, PHY 8, AC 39416 A, SM 686. Data were analyzed statistically for morphological, growth, yield and biochemical parameter viz. leaf rolling, plant height, grain yield, total dry matter and proline accumulation. The pots were arranged in completely randomized design with three replications. Drought stress caused increase in percent reduction of plant height, grain yield and total dry matter. On the other hand, fold increase of leaf rolling and proline accumulation was recorded in all rice genotypes as compared to control. The genotype IET 24098 showed maximum percent reduction in plant height, grain yield and total dry matter production while minimum was recorded in the genotype AC 39416A.However, leaf rolling and proline accumulation was increased in all rice eight rice genotype under drought stress. The minimum and maximum fold increase of leaf rolling and proline accumulation was recorded in the genotype AC 39416Arespectively while minimum fold increase of proline was recorded in the genotype IET 24098.The study revealed that the genotype AC 39416A may possess drought tolerance characteristic while the genotype IET 24098 may be drought sensitive based on growth, yield, leaf rolling and proline accumulation behavior which might be due to their genetic differences.

\section{Introduction}

Rice (Oryza sativa L.) is one of the most dominant cereal food crops worldwide. It is estimated that about $50 \%$ of the world rice is affected by drought (Bouman et al., 2005). Drought is the most crucial and major abiotic stress limitation for rice production Drought 
is one of the environmental stress which significantly restricts the plant growth and crop productivity in most agricultural fields of the world (Tas and Tas, 2007). Most typical symptoms of drought stress arethe reduction of plant growth. It reduces the plant growth by affecting various morphological, physiological, and biochemical process such as decrease in photosynthesis rates, transpiration rate, water use efficiency, internal $\mathrm{CO}_{2}$ concentration, relative water content and membrane stability index (Mishra et al., 2018; Zhu et al., 2020). Free amino acid accumulation and production of proline by plant tissue is an as adaptive response. Thus, proline can be used as metabolic marker in relation to stress (Saha et al., 2019). Furthermore, proline helps in stabilizing subcellular structures, scavenging free radicals and buffer cellular redox potential under drought stress conditions thereby maintains turgor and stimulates continued growth under stress (Swapna et al., 2017). The aim of this study was to study the effects of drought stress on growth, yield, and accumulation of proline in rice genotypes.

\section{Materials and Methods}

A pot experiment was conducted in the Garden Section of Department of Plant Physiology, G.B. Pant University of Agriculture and Technology, Pantnagar. Seeds of eight rice genotypes viz. IET 24098, IET 24100, PHY 5, PHY 6, PHY 7, PHY 8, AC 39416 A, SM 686 were obtained from Directorate of Rice Research, Rajendranagar, Hyderabad. Half loamy and half compost soil were used by mixing of soil to fill pots.

The nursery of seeds was raised and three seedlings per pot was planted. Drought stress was imposed by withholding water for three days at the stage of flowering. Water level in well-watered treatment (control) was maintained at $5 \mathrm{~cm}$ above the surface of soil.
Field capacity of soil and soil moisture contents on third day of drought stress was measured by Time Domain Reflectometer (TDR). Field capacity of soil was $47.5 \%$ while soil moisture content was $5 \%$ under drought stress. Growth parameters like plant height, total dry matter, grain yield was determined. Leaf rolling score was also measured. It was scored visually using 0 to 5 with one being the first evidence of rolling and five being a closed cylinder. Accumulation of proline in drought stress was determined in fresh flag leaves of rice genotypes by the method of Bates et al. (1973).

The mean values were taken from measurements of three replicates and standard error (SE) of the means was calculated. Data collected were analyzed statistically using Analysis of Variance (ANOVA) method using STPR2 software. The experiment was by laid out by completely randomized design with three replications of each control and treatment.

\section{Results and Discussion}

Drought stress increased the leaf rolling among all the rice genotypes (Fig. 1). Visual scoring is a reliable measure of tolerance for the estimation of oxidative damage in plants. When drought stress develops, the plants naturally evolve a defensive mechanism for abbreviating the energy load on the leaf (Chaturvedi et al., 2012) and experienced leaf rolling to reduce net radiation load on the leaf. In rice, leaf rolling under drought stress was studied as one of the best criterion in estimating drought tolerance (Pandey and Shukla, 2015). In this study, the genotype AC 39416A, PHY 7, PHY 8 expressed less leaf rolling than other rice genotype while maximum leaf rolling was recorded in the genotypes IET 24098 and IET 24100.The maximum folds increase of leaf rolling was 
found in genotypes IET 24100 followed by IET 24098 while minimum was found in the genotype AC 39416A. Rolling of leaf is one of the acclimation responses of rice and is used as a criterion for screening drought tolerance. Leaf rolling is hydronasty that leads to reduced light interception, transpiration, and leaf degradation (Kadiogles and Terzi, 2007). It may help in maintaining internal water status of the plant (Gana, 2011; Ha, 2014). If the turgor pressure of cell it maintained under drought stress, it will result in delayed leaf rolling. However, increased leaf rolling has the advantage of preventing water loss and radiation damage under severe stress. Thus, leaf rolling is an adaptive response in rice under water deficit condition and leaf angle character is usually associated with plasticity in leaf rolling when internal water deficit occur (Chutia and Borah, 2012).

Drought stress reduced the plant height and varied among all the rice genotypes (Fig 2). The maximum plant height was recorded in the genotype PHY 4 and minimum was recorded in the genotype IET 24098 under drought stress. The maximum percent reduction of plant height was recorded in the genotype IET $24098 \quad(23.67 \%)$ while minimum was recorded in the genotype AC 39416A (1.34\%). The plant height is a genetic character which is also controlled by environmental factors. Plant height in rice is dependent on culm elongation, internode number per plant and elongation of leaf and leaf blade. The drought stress reduces the metabolic activity due to lack of water. Such due to reduced turgor pressure affects the cell division and cell elongation activities of plant and plant height reduces. The results agree with Islam et al., 2001; Sikuku et al., 2012. The magnitude of reduction is dependent on the genotype.

Drought stress decreased the grain yield in all the rice genotypes (Fig. 3). The maximum grain yield was recorded in the genotype PHY $7(7.92 \mathrm{~g} /$ plant $)$ while minimum was recorded in the genotype PHY 6(3.81 g/plant) under drought stress. However maximum and minimum percent reduction was recorded in the genotype IET 24098 and AC 39416A, respectively. Under drought stress, phonological, physiological and yield traits are important determinants of grain yield (Barnaby et al., 2019). Earliest reports suggests that there is decrease in plant height by $11.87 \%$ during drought stress. Drought stress at vegetative stage reduces water content and lower leaf potential leading to reduced turgor, conductance and photosynthesis and reduce grain yield (Akbarian et al., 2011 and Amini et al., 2014). In the experiment, drought stress was severe enough to reduce grain yield to greater extent. The result showed genotypic variation in grain yield in drought tolerant cultivar(Torres and Henry, 2018).Reduction in productivity might be due to decrease in rate of $\mathrm{CO}_{2}$ assimilation, decrease in conductance via stomata, photosynthetic pigments, leaf short size, reduced water status, decrease in activities of enzyme which synthesize sucrose and starch, which leads to a decrease in yield (Anjum et al., 2011). Grain yield reduction in rice might be due to inhibition of photosynthesis rate and reduced translocation of assimilated products due to less soil moisture. The results agree with Sarvestani et al., 2008; Pantuwan et al., 2000 reported that grain yield of some rice varieties was reduced by up to $81 \%$ under drought condition and this reduction is dependent on timing, duration, and severity of plant stress.

Total dry matter was also decreased among the rice genotypes under drought stress (Fig. 4). The maximum total dry matter was recorded in the genotype IET 24100(39.97 $\mathrm{g} / \mathrm{pot}$ )while minimum was recorded in the genotype IET 24098(29.57\%). Maximum percent reduction of total dry matter was 
recorded in the genotype IET 24098 (39.86\%) while minimum was recorded in the genotype IET $24100(13.80 \%)$ followed by the genotype AC 39416A (15.4\%). Results suggested that total dry matter also decreased under drought stress as compared to control. The inhibition of photosynthesis rate might be reason of decrease in total dry matter under drought stress. The results are in confirmation with previous workers (Hossain, 2001).

Fig.1 Leaf rolling of different rice genotypes under control and drought stress treatment

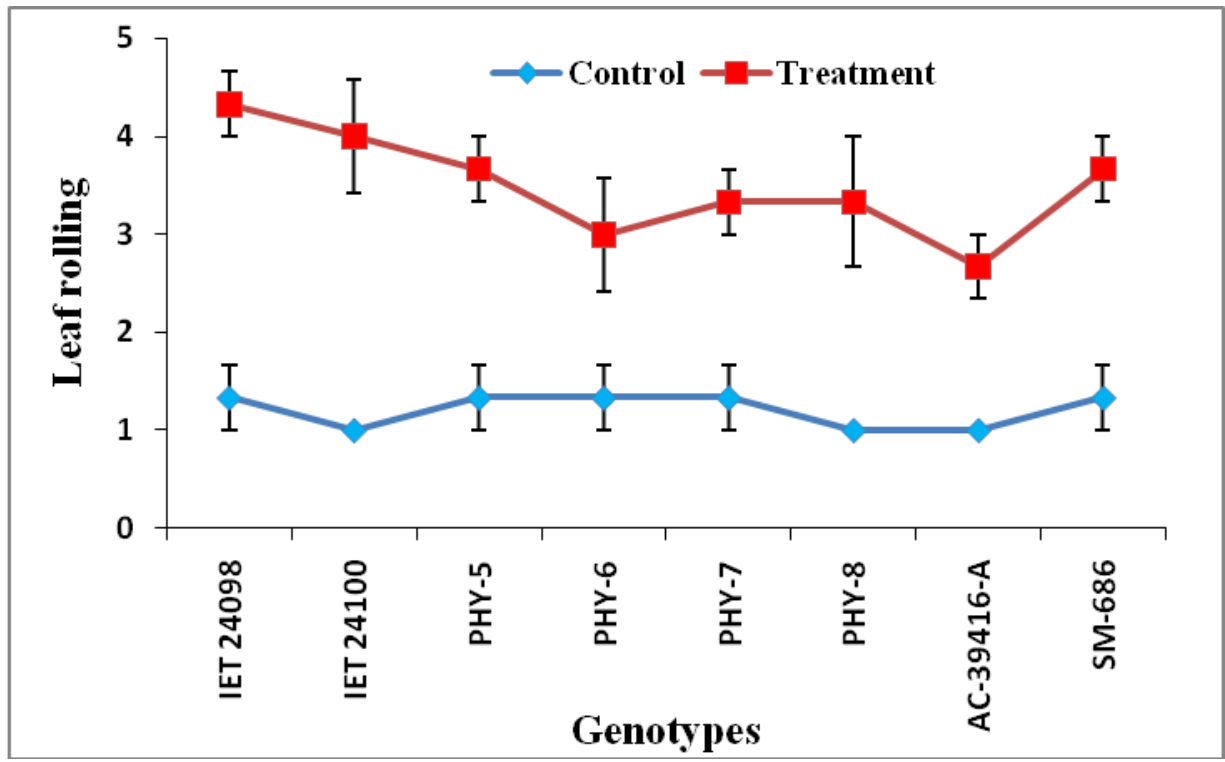

Fig.2 Plant height at flowering of different rice genotypes under control and drought stress treatment

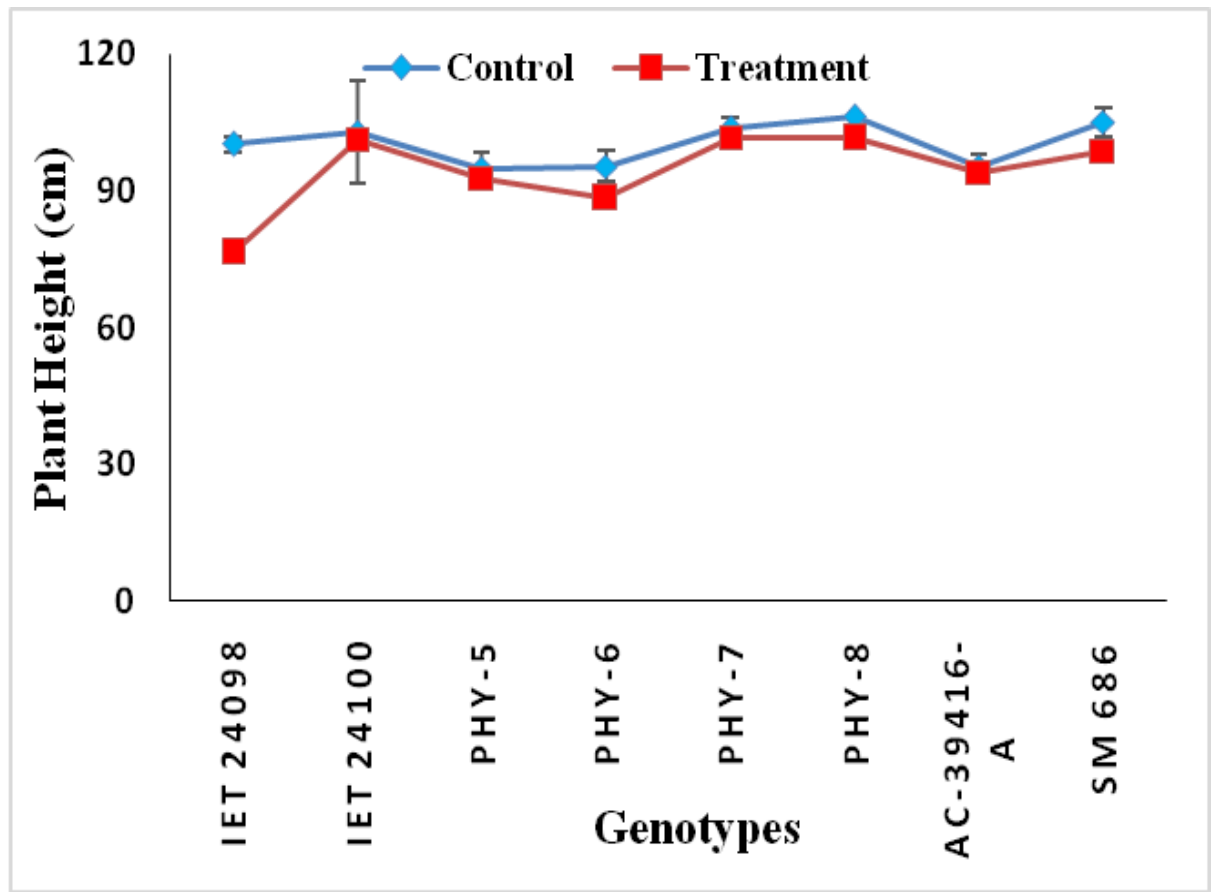


Fig.3 Grain yield (g/plant) of different rice genotypes under control and drought stress treatment

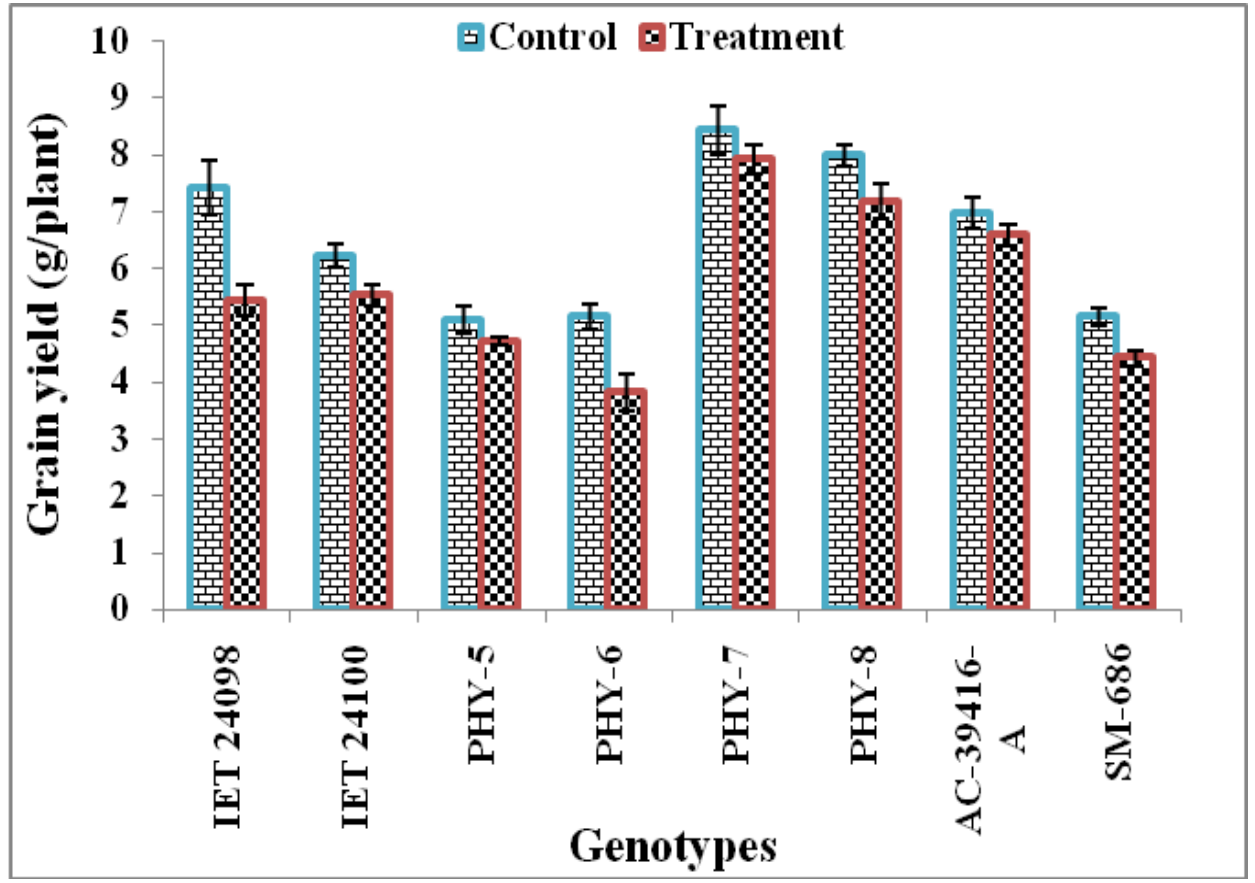

Fig.4 Total dry matter (g/pot) of different rice genotypes under control and drought stress treatment

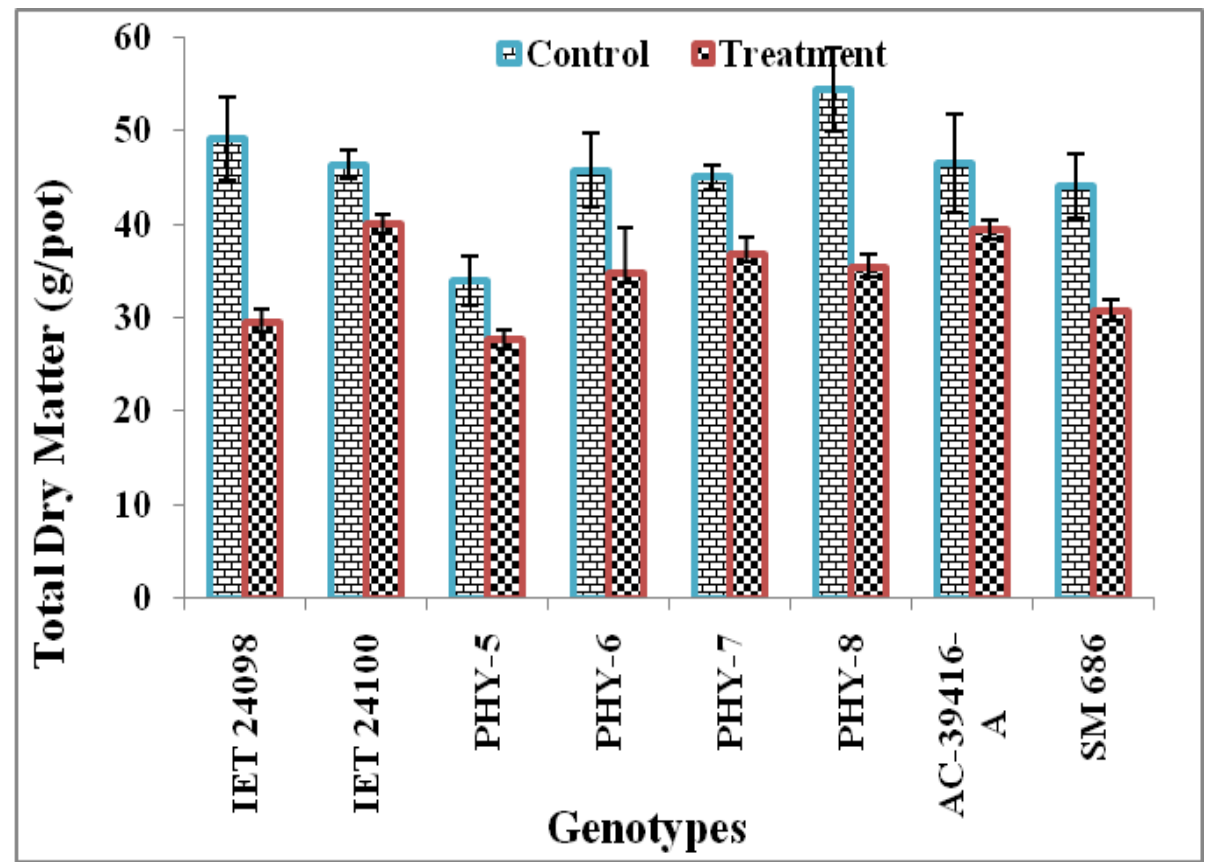


Fig.5 Total proline content of different rice genotypes under control and drought stress treatment

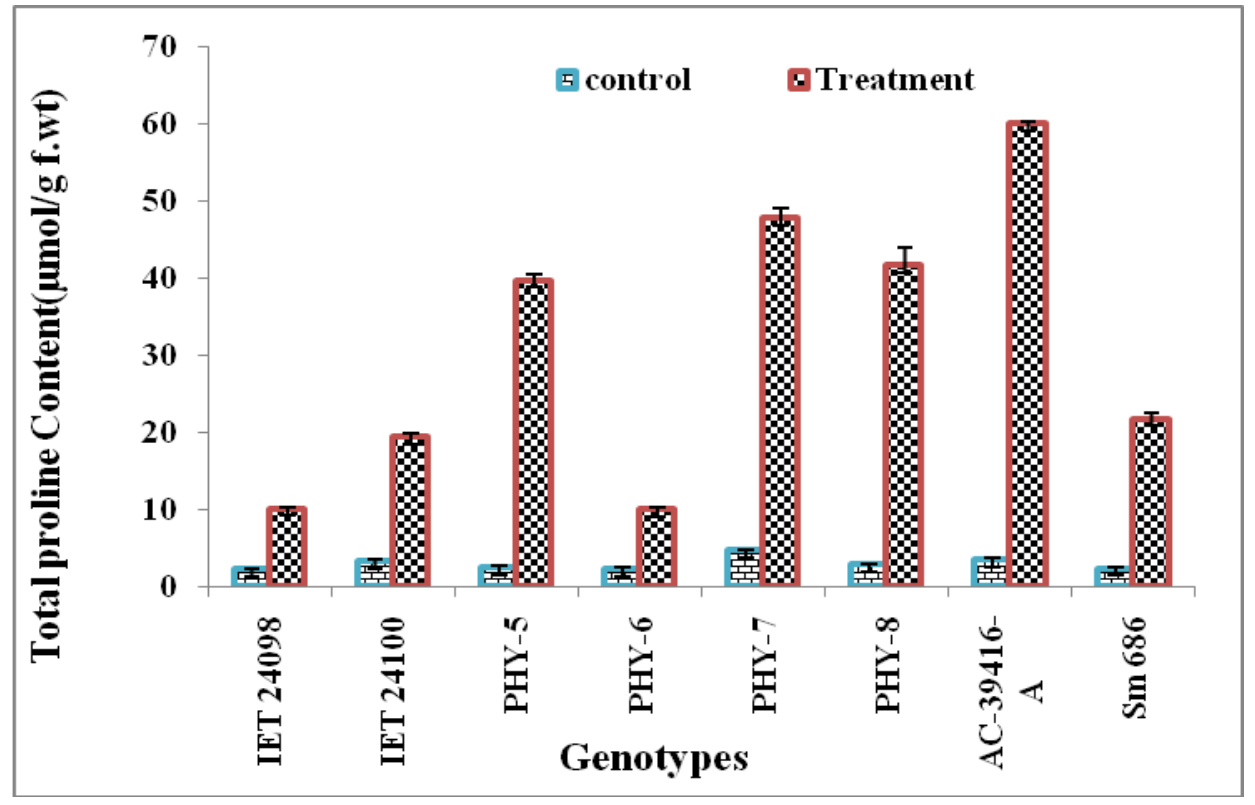

The proline content increased in all the rice genotypes under drought stress as compared to that in control (Fig. 5). Under drought stress, maximum proline content was recorded in the genotype AC 39416A $(30.08 \mu \mathrm{mol} / \mathrm{g}$ fresh wt.)while minimum was recorded in the genotype IET 24098(5.10 $\mu \mathrm{mol} / \mathrm{g}$ fresh wt.).The maximum and minimum fold increase of proline was recorded in the genotype AC 39416A (8.45 folds) and IET 24098(2.23 folds) respectively. Accumulation of proline content under drought stress indicates accumulated proline might act as compatible solute regulating and reducing water loss from the plant cell during water deficit condition(Yokota et al., 2006) and play key role in osmotic balance (Fedina et al., 2002). Proline accumulates under stress supplies energy for survival and plant growth and thereby helps the plants to tolerate stress condition(Kumar et al., 2011).Thus, the proline content is a good indicator for screening drought tolerant varieties in water deficit condition (Bayoumi et al., 2008; Kumar et al., 2011; Rahdari et al., 2012). The increase in proline level may help to maintain osmotic potential of cytoplasm of cells which is important for survival of plants under stress (Sahaet al., 2016). Accumulation of proline has been advocated as a parameter of selection for stress tolerance (Jaleel et al., 2007).

In conclusion, drought stress highly reduced plant height, grain yield, total dry matter while leaf rolling and proline accumulation was increased under drought stress. The genotype AC 39416A showed minimum growth and yield reduction while the genotype IET 24098 showed maximum reduction under drought stress. Similarly, less leaf rolling and maximum proline accumulation was recorded in the genotype AC 39416A while maximum leaf rolling and minimum proline accumulation was recorded in the genotype IET 24098.This study suggests that the genotype AC 39416A may possess drought tolerance characteristic while the genotype IET 24098 may be drought sensitive among all the genotype based on their growth and proline accumulation. The tolerance attribute is due to their genotypic variability in genotypes. 


\section{Acknowledgement}

The authors are thankful to the All India Coordinated Rice Improvement Programme of ICAR, Directorate of Rice Research Rajendranagar Hyderabad, Director Experiment Station Pantnagar and Dean College of Basic Sciences and Humanities G.B. Pant University of Agriculture and Technology, Pantnagar for providing the necessary facilities for conducting the present investigation.

\section{References}

Akbarian, A., Arzani, A., Salehi, M. and Salehi, M. 2011. Evaluation of triticale genotypes for terminal drought tolerance using physiological traits. Indian Journal of Agricultural Sciences, 81 (12): 11101115

Amini, H., Arzani, A. and Karami, M. 2014. Effect of water deficiency on seed quality and physiological traits of different safflower genotypes. Turkish Journal of Biology, 38: 271-282.

Anjum, S.A., Xie, X.Y., Wang, L.C., Saleem, M.F., Man, C. and Lei, W. 2011. Morphological, physiological, and biochemical responses of plants to drought stress. Afr J Agric Res, 6(9): 2026-2032.

Barnaby, J.Y., Rohila, J.S., Henry, C.G., Sicher, R.C., Reddy, V.R. and McClung, A. M. 2019. Physiological and metabolic responses of rice to reduced soil moisture: Relationship ofwater stress tolerance and grain production. International Journal of Molecular Sciences, 20(8): 1-20.

Bates, L.S., Walden, R.P. and Teare, J.B. 1973. Rapid determination of free proline for water stressed studies. Plant and Soil, 39: 205-207.

Bayoumi, T., Eid, M.H. and Metwali, E. 2008. Application of physiological and biochemical indices as a screening technique for drought tolerance in wheat genotypes. African Journal of
Biotechnology, 7(14): 2341-2352.

Bouman, B.A.M., S. Peng, A.R. Castaoeda and R.M. Visperas. 2005. Yield and water use of irrigated tropical aerobic rice systems. Agricultural Water Management, 74(2): 87-105.

Chaturvedi, G.S., Singh, A. and Bahadur, R. 2012. Screening techniques for evaluating crop germplasm for drought tolerance. Plant Arch, 12(1): 11-18.

Chutia, J. and Borah, S.P. 2012. Water stress effects on leaf growth and chlorophyll content but not the grain yield in traditional rice (Oryza sativa Linn.) genotypes of Assam, India: II. Protein and proline status in seedlings under PEG induced water stress. Am. J. Plant Sci., 3(7): 971-980

Fedina, I.S., Georgieva, K. and Grigorova, I. 2002. Light-dark changes in proline content of barley leaves under salt stress. Inst. Plant Physiol., 45(1): 59-63.

Gana, A.S. 2011. Screening and resistance of traditional and improved cultivars of rice to drought stress at Badeggi, Niger State, Nigeria. Agric. Biol. J. North. Am., 2(6): 1027-1031.

Ha, P.T.T. 2014. Physiological responses of rice seedlings under drought stress. J. Sci. Devel., 12(5): 635-640.

Islam, M.T. and Gretzmacher, R. 2001. Grain growth pattern and yield performance of some transplanted aman rice cultivars in relation to moisture stress. B.J. Nuclear. Agric., 16-17:21-28.

Jaleel, C.A., P. Manivannan, A. Kishorekumar, B. Sankar, R. Gopi, R. Somasundaram and R. Panneerselvam, 2007. Alterations in osmoregulation, antioxidant enzymes and indole alkaloid levels in Catharanthus roseus exposed to water deficit. Colloids Surf. B: Biointerfaces, 59: 150-157.

Kadiogles, A and Terzi, R. 2007. A dehydration avoidance mechanism: Leaf rolling. Bot. Rev., 73(4): 290-302

Kumar, R.R., Karajol, K. and Naik, G.R. 2011. Effect of polyethylene glycol induced water stress on physiological and 
biochemical responses in pigeon pea (Cajanus cajan L. Mill sp.). Recent Res. Sci. Tech., 3(1): 148-152.

Mishra, S.S., Behera, P.K., Kumar, V., Lenka, S.K. and Panda, D. 2018.Physiologicalcharacterization and allelic diversity of selected drought tolerant traditional rice (Oryza sativa L.) landraces of Koraput, India. Physiol. Mol. Biol. Plants, 24(6): 1035-1046

Pandey, V. and Shukla, A. 2015. Acclimation and tolerance strategies of rice under drought stress. Rice Sci., 22(4): 147-161.

Pantuwan, G, Fukai S, Copper M, Rajatasereekul and S, O'Toole JC 2000. Field screening for drought resistance in increased lowland rice production in the Mekong region. Proceedings of international workshop, 69-77

Rahdari, P., Hosseini, S.M. and Tavakoli, S. 2012. The study effect of drought stress on germination, proline, sugar, lipid, protein, and chlorophyll content in purslane (Portulaca oleracea L.) leaves. J. Med. Plants Res., 6(9): 1539-1547.

Saha, S., Begum, H.H. and Nasrin, S. 2019. Effects of Drought Stress on Growth and Accumulation of Proline in Five Rice Varieties (Oryza Sativa L.). Journal of the Asiatic Society of Bangladesh, Science, 45(2): 241-247.

Saha, S., Samad, R. Rashid, P. and Karmoker, J.L. 2016. Effects of sulphur deficiency on growth, sugars, proline, and chlorophyll content in Mung bean (Vigna radiata L. var. BARI MUNG-6). Bangladesh J. Bot.,45: 405-410

Sarvestani, Z.T., Pirdashti, H., Sanavy, S.A. and
Balouchi, H. 2008. Study of water stress effects in different growth stages on yield and yield components of different rice (Oryza sativa L.) cultivars. Pakistan journal of biological sciences: PJBS, 11(10), 1303-1309.

Sikuku, P.A., Onyango, J.C. and Netondo, G.W. 2012. Physiological and biochemical responses of five nerica rice varieties (Oryza sativa L.) to water deficit at vegetative and reproductive stage. Agric.

Biol. J. North Am., 3(3): 93-104

Swapna S. and Shylaraj KS. 2017. Screening for Osmotic Stress Responses in Rice Varieties under Drought Condition. Rice Science, 24(5): 253-263.

Tas, S. and Tas, B. 2007. Some physiological responses of drought stress in wheat genotypes with different ploidity in Turkiye. World J. Agri. Sciences, 3: 178183.

Torres, R.O. and Henry, A. 2018. Yield stability of selected rice breeding lines and donors across conditions of mild to moderately severe drought stress. Field Crops Research, 220: 37-45.

Yokota, A., Takahara,K. and Akashi, K. 2006. Physiology and molecular biology of stress tolerance in plants. In: Madhavarao, K. Raghavendra and K. Janardhanreddy (eds), pp15-40, Springer.

Zhu, R., Wu, F.Y., Zhou, S., Hu, T., Huang, J. and Gao, Y. 2020. Cumulative effects of drought-flood abrupt alternation on the photosynthetic characteristics of rice. Environ Exp Bot, 169: 103901.

\section{How to cite this article:}

Kalpana Maurya, Hem C. Joshi, S.C. Shankhdhar, S. K. Guru, A.K. Guar, M.K. Nautiyal and Atul Kumar. 2021. Evaluation of Some Rice (Oryza sativa L.) Genotypes for Drought Tolerance. Int.J.Curr.Microbiol.App.Sci. 10(02): 3294-3301. doi: https://doi.org/10.20546/ijcmas.2021.1002.362 